its type in Great Britain and which would at that time bear comparison with the best of its kind in Europe. It has housed a long list of distinguished professors, each of whom added an important quota to his science. Thus in chemistry we see the names Aufield, 1862 ; Tilden, 1865 ; Palmer Wynne, 1896; Collie, 1902 ; Crossley, 1904 ; and Dunstan, 1905; and in botany those of such figures as Robert Bentley, 1849, and Reynolds Green, 1887. In pharmacy and materia medica came Pereira, Redwood, Ince, Greenish and Wallis. The early days of the School saw the development of the use of the microscope by Greenish in the evaluation of powdered drugs. Its latter years saw the establishment, by Burn, of pharmacological laboratories for research work in methods of biological assays, and the years between had a record of steady achievement which was marked in 1926 by the recognition of the School by the University of London as a School of the University and by the establishment of a degree in pharmacy.

The reconstitution of the School brings to an end a fruitful regime of a hundred and six years, and inaugurates a new era which it is hoped to make even more productive of benefit to pharmacy than the old. Under its new title, the School will have an independent existence with a new governing body, a Council which will consist of the Dean (Prof. H. Berry), together with the following members: (a) nominated by the University of London: Dr. O. L. Brady, Sir Archibald Gray, Mr. John Hunter and Dr. G. B. Jeffery; (b) nominated by the Academic Board of the College: Prof. G. A. H. Buttle, Dr. Katharine Coward, Dr. J. W. Fairbairn and Prof. W. H. Linnell; (c) nominated by the Pharmaceutical Society: Mr. W. S. Howells, Mrs. J. C. Irvine, Mr. H. N. Linstead and Mr. C. W. Maplethorpe; together with three co-opted members : Sir Henry Dale, Mr. W. J. C. Quarrell and Sir Harry Jephcott, who becomes chairman of the new School Council. Mr. S. R. Curtis has been appointed secretary to the School.

\section{BRITISH EMPIRE CANCER CAMPAIGN}

$\mathrm{T}$ HE twenty-fifth annual report of the British Empire Cancer Campaign covers the work done during the latter half of 1947. To those not acquainted with the ramifications of modern cancer research, much of the work in the report will occasion surprise, owing to its apparent lack of connexion with the subject. But the fact is that the problem of malignant growth is inextricably bound up with peculiarities of cellular respiration, nutritional requirements, hormone balance and interaction of enzyme systems; and its study demands contributions from almost every branch of science.

In the sphere of radiation physics, work has been mainly concerned with preparing the way for the future use of high-voltage radiation and of radioactive isotopes. To this end refinements of methods for accurate measurement of dosage, which becomes of increasing difficulty and importance under these conditions, have been developed. Measurements of extraneous radiations likely to harm personnel engaged in radiation therapy have also been carried out. During the year, further studies have been made on the biological effects of radiations. The extreme rapidity with which cellular changes occur is astonishing. Thus Prof. J. S. Mitchell has shown that within seven minutes of exposing cultures of chick embryo fibroblasts to $\mathrm{X}$-irradiation, alterations occur in the amount of substances in the cells which cause absorption of ultra-violet light of wave-length 2537 A. Ribose nucleic acid is believed to be largely responsible for such absorption; but the possibility that other substances may be concerned is receiving attention. By standard histological methods pyenotic changes in the cell nuclei of the membrana granulosa of large ovarian follicles can be demonstrated within four hours of irradiating rats (L. Halberstaedter and M. Ickowicz). By the use of radioactive phosphorus $\left(\mathbf{P}^{32}\right)$ uptake as a measure of thymonucleic acid formation, Mrs. B. E. Holmes has adduced evidence that therapeutic doses of X-rays reduce the synthesis of this substance, and that this reduction may be an integral part of the damaging effects of radiations. On the clinical side, an important practical outcome of A. Glücksmann and L. G. Spear's histological method of assessing the progress of radiation therapy in cancer of the cervix uteri has been that, on the strength of it, several cases have been submitted to radical surgery, irradiation having been abandoned although in some cases the clinical response seemed favourable. In every case examination of the operation specimens showed the malignant process to be active.

Among the clinical reports is an analysis from Birmingham of survival-rates of 1,367 cases of cancer of the breast observed between 1936 and 1942. The accepted clinical opinion that the results of surgery combined with radiotherapy are superior to those of either form of treatment alone receives statistical confirmation. Owing to the small numbers, however, it is not possible to decide whether pre-operative or post-operative irradiation is the more effective method; though in the series quoted, post-operative treatment gave the better results. From St. Mark's Hospital come some important figures relating to cancer of the rectum. Of 716 cases treated between 1928 and 1941, just under half survived five years or more. But the five-year survival-rate of cases with disease confined to the rectum was more than 80 per cent, whereas those in which lymphatic metastases were present had a five-year survival-rate of just over 25 per cent. The correlation between the histological appearance of the growths and the extent of metastases was high in this series. Lymph. atic spread was present in 80 per cent of cases in which 'high grade' malignancy was reported histologically; but in only 20 per cent of those reported as 'low grade'. In a very full report by the Clinical Cancer Research Committee on malignant disease of kidney, bladder and prostate, the figures concern cases treated before oestrogen therapy had been introduced for the last-named disease, and will therefore be useful for comparison with similar figures when the results of such treatment are available.

Sir Ernest Kennaway's study of the effect of circumcision on the subsequent development of cancer of the penis has already excited comment in the medical Press. He finds that the operation protects against eancer if performed at eight days, but confers no protection when carried out after the fourteenth year. "The failure of the operation deferred until the 14th year to give the protection given by it when carried out on the 8 th day suggests that the train of events leading to malignant growth is set going early in life, and that removal of the cause 
does not then avert the development of cancer at a much later age." In the experimental field the component processes which constitute "the train of events leading to malignant growth" have been characterized with greater clarity during the last fifteen years. Dr. I. Berenblum and Dr. P. Shubik have now placed such studies on a quantitative footing. Dr. Berenblum had earlier shown that croton oil, itself non-carcinogenic, would cause growths to appear when painted on the skin of mice previously treated with doses of known carcinogens insufficient to provoke neoplasia. The late Dr. J. C. Mottram showed that a single painting of carcinogen was effective when followed by croton oil applications. Using different carcinogens and varying the number and frequency of croton oil applications, Berenblum and Shubik have shown that two entirely distinct mechanisms enter into the carcinogenetic process in mouse skin. The initial painting with carcinogen produces some invisible, irreversible alteration in a few of the cells of the painted area-the 'initiating' process. The 'initiated' cells remain dormant until stimulated into activity by a 'promoting' agent-in these exporiments croton oil. The recognition of these two stages explains certain discrepancies which have been encountered in assessing the carcinogenic potency of certain compounds. A compound may be a powerful initiator but a poor promoter. If its activity is measured in terms of minimal dose response it will be labelled a powerful carcinogen, since this measurement is essentially that of initiating action; whereas if average latent period for tumour production is the measurement chosen, its activity will be poor, average latent period indicating promoting action.

Of medical interest is the finding of workers in Oxford that liquor picis carb. B.P., a commonly used coal-tar preparation, sometimes prescribed for long periods, contains 0.02 per cent benzpyrene, and produced papillomas in ten weeks when painted twice weekly on mouse skin. After twenty-six weeks, 50 per cent of survivors had tumours, more than half of which became malignant.

Further work on recently discovered carcinogens has been done during the year. A curious property of 2-acetylaminofluorene, namely, the production of epitheliomas of the external auditory meatal wall, is shared by 4-dimethylaminostilbene. Taking advantage of the characteristic brilliant fluorescence of the latter compound in ultra-violet light, Glasgow workers have shown that it is excreted in the cerumen, which would account for the unusual site of tumour growth.

Work on growth inhibitors at the Royal Cancer Hospital has been considerably extended. 4-N : $\mathrm{N}$. di-(2 chloroethyl)-aminostilbene, which possesses the chloroethyl groups characteristic of the nitrogen mustards, has a marked but short-lived inhibitory effect on the Walker rat carcinoma. The $\mathrm{N}: \mathrm{N}$-di2-chloroethyl side-chain was introduced into many aromatic amines, and marked inhibitory activity has been demonstrated in the aniline, $o-, m$ - and $p$-toluidines, $o$ - and $p$-anisidine, $\beta$-naphthylamine, and $p$-aminobenzoic acid derivatives.

Much work is presented on tumour viruses. Prof. R. D. Passey and his colleagues at Leeds have examined extracts of tissues from breast tumours, and normal tissues from high-and low-cancer strain mice by means of electron microscopy. Extracts made from all tissues and from the milk of highcancer strains consistently show numerous spherical

particles of the order of $250 \mathrm{~A}$. diameter. These particles are absent, or only present sporadically, in similar material from low-cancer strains. Ultracentrifugation at $60,000-120,000 \mathrm{~g}$ removes the particles from the extracts. Even after the drastic process of extraction employed, the samples in which the particles are numerous incite mammary tumours when inoculated into susceptible mice. The particles are thus closely associated with milk-factor activity; but the authors stress the need for caution in interpreting the findings.

The British Journal of Cancer, which is sponsored by the Campaign, has now completed a year of publication and gives an indication of the quality and breadth of cancer research in Britain. The present report includes work from new centres, such as the University of Bristol, the Hebrew University at Jerusalem and the University of Glasgow, which indicate how the activities of the Campaign are still growing twenty-five years after its foundation.

D. A. G. GaLton

\section{AN ELECTRON MICROSCOPE STUDY OF CELLULOSE IN THE WALL OF VALONIA VENTRICOSA}

\section{By DR. R. D. PRESTON and DR. E. NICOLAI Botany Department \\ AND}

\author{
DR. R. REED and A. MILLARD \\ Department of Biomolecular Structure, \\ University of Leeds
}

$\mathrm{D}$ URING the past thirty years or so, intensive investigation of cellulose by various physical methods has directed attention repeatedly to the possible existence of supermolecular units of structure ranging from 'fibrils' 1 some $0.4 \mu$ in diameter and of indefinite length to small spherical or ellipsoidal particles of diameter up to $1 \cdot 5 \mu^{2}$.

While this has lent colour to speculations by earlier workers based largely on microscopical observations $^{8}$, it has never been clear that the newer physical methods yielded any more precise a picture of these units than did mere microseopical observation; nor, indeed, could it be claimed that proof had ever been given of the concrete existence of any such units in the intact, untreated walls of plant cells. With the advent of electron microscopy, however, and especially following the notable advance in manipulative technique using metal shadowing and surface replication, it became at last possible to make a direct attack on this particular aspect of cellulose structure.

Few of the many existing electron micrographs of cellulose have been very informative other than to show that, under suitable treatment, cellulose can be broken down into fibrous bodies. This has been due largely to the unfortunate choice for experimental material of either drastically treated celluloses such as filter paper or of mechanically disintegrated cellular tissues which are difficult to manipulate and the photographs of which are, by their very nature, almost uninterpretable ${ }^{4}$. 